\title{
Correction to: Celastrol mediates autophagy and apoptosis via the ROS/JNK and Akt/mTOR signaling pathways in glioma cells
}

Xihong Liu ${ }^{1,2}$, Peiyuan Zhao ${ }^{4}$, Xiujuan Wang ${ }^{1,2^{*}}$, Lei Wang ${ }^{1,2}$, Yingjun Zhu ${ }^{1,2}$, Yadi Song ${ }^{1,2}$ and Wei Gao ${ }^{1,2,3^{*}}$

\section{Correction to: J Exp Clin Cancer Res (2019) 38:184 https://doi.org/10.1186/s13046-019-1173-4}

In the original publication of this article [1], there are two errors.

The first error is in author affiliation information. The corrected author affiliation information is as given hereafter:

Xihong Liu1, Peiyuan Zhao4, Xiujuan Wang1*, Lei Wang1, Yingjun Zhu1, Yadi Song1 and Wei Gao1,2,3*.

1 School of Traditional Chinese Medicine, Beijing Key Lab of TCM Collateral Disease Theory Research, Capital Medical University, Beijing, China.

2 School of Pharmaceutical Sciences, Capital Medical University, Beijing, China.

3 Advanced Innovation Center for Human Brain Protection, Capital Medical University, Beijing, China.

4 Basic Discipline of Integrated Chinese and Western Medicine, Henan University of Chinese Medicine, Henan, China.

The second error is in Fig. 8d (panel 2 of Tunel assay, group of $1 \mathrm{mg} / \mathrm{kg} \mathrm{Cel)}$. The revised Fig. 8 which includes $8 \mathrm{~d}$ has now been included in this correction.

The correct Fig. 8 is given hereafter:

The error: In the initially published version of this article, the picture in the Tunel assay of Cel $(1 \mathrm{~kg} / \mathrm{mg})$ group are the same with that in Cel $(2 \mathrm{~kg} / \mathrm{mg})$ group in Fig. $8 \mathrm{~d}$.

This error does not affect discussions and conclusions drawn in the article.

\section{Author details}

${ }^{1}$ School of Traditional Chinese Medicine, Capital Medical University, Beijing, China. ${ }^{2}$ Beijing Key Lab of TCM Collateral Disease Theory Research, Capital
Medical University, Beijing, China. ${ }^{3}$ Advanced Innovation Center for Human Brain Protection, Capital Medical University, Beijing, China. ${ }^{4}$ Basic Discipline of Integrated Chinese and Western Medicine, Henan University of Chinese Medicine, Zhengzhou, Henan, China.

Published online: 02 July 2019

\section{Reference}

1. Liu X, et al. Celastrol mediates autophagy and apoptosis via the ROS/JNK and Akt/mTOR signaling pathways in glioma cells. J Exp Clin Cancer Res. 2019;38:184.

*Correspondence: wxj0517@sina.com; weigao@ccmu.edu.cn

${ }^{1}$ School of Traditional Chinese Medicine, Capital Medical University, Beijing,

China

Full list of author information is available at the end of the article

(c) The Author(s). 2019 Open Access This article is distributed under the terms of the Creative Commons Attribution 4.0 International License (http://creativecommons.org/licenses/by/4.0/), which permits unrestricted use, distribution, and reproduction in any medium, provided you give appropriate credit to the original author(s) and the source, provide a link to the Creative Commons license, and indicate if changes were made. The Creative Commons Public Domain Dedication waiver (http://creativecommons.org/publicdomain/zero/1.0/) applies to the data made available in this article, unless otherwise stated. 


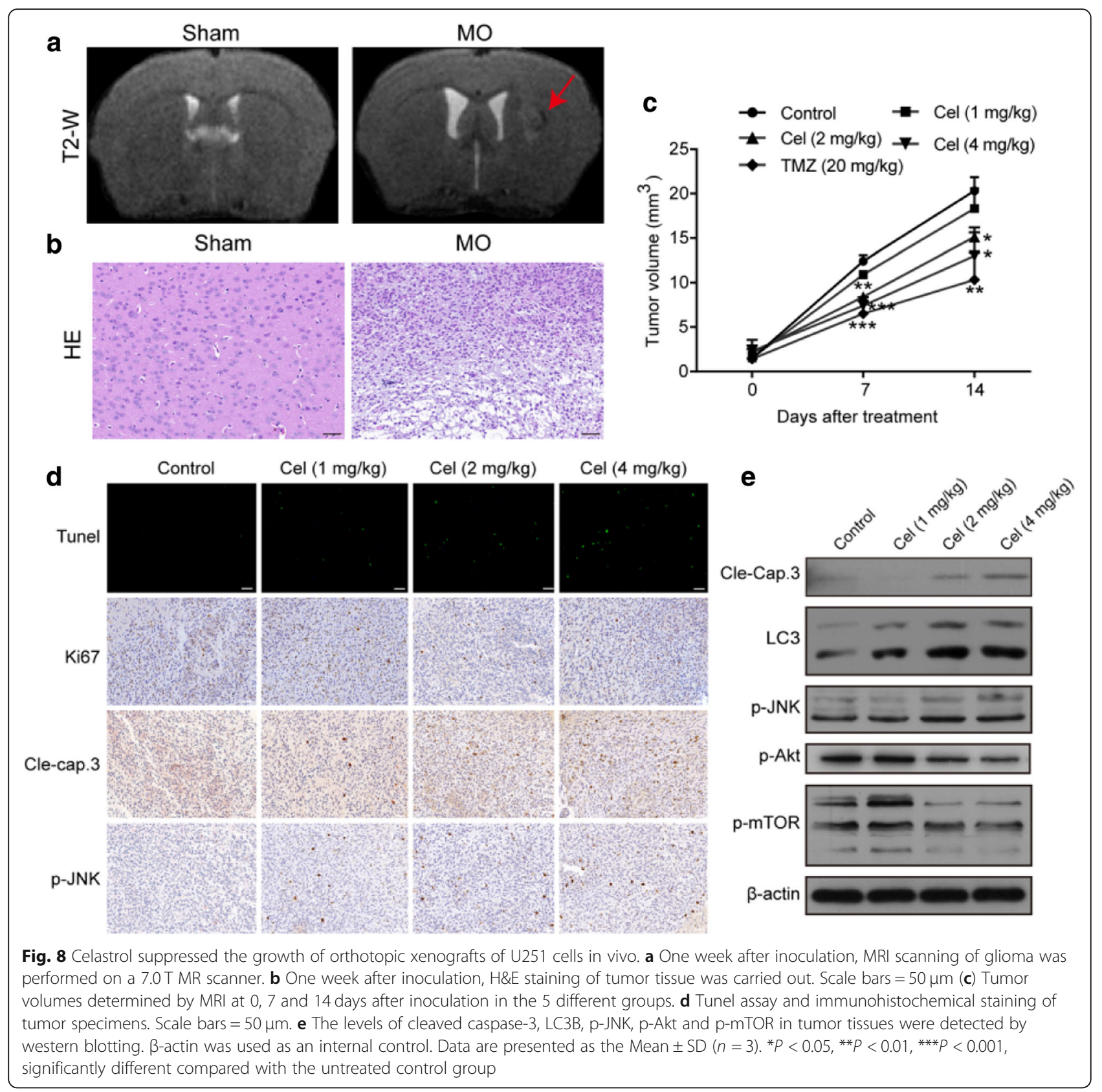

